\title{
Decrepitating salt of Wieliczka
}

\section{H. Rose}

To cite this article: H. Rose (1840) Decrepitating salt of Wieliczka, Philosophical Magazine Series 3, 17:110, 318-319, DOI: 10.1080/14786444008650181

To link to this article: http://dx.doi.org/10.1080/14786444008650181

册 Published online: 01 Jun 2009.

Submit your article to this journal $\pi$

LII Article views: 3

Q View related articles $₫$ 
a temperature of $86^{\circ}$ to $95^{\circ}$ Fahrenheit; after some hours the liquid is to be poured off, the membrane is to be again similarly digested, and to be treated with cold water till it exhales a putrid odour; it is then to be filtered; the filtered liquor is transparent, slightly viscid, and exhibits a remarkable digestive power when a small quantity of hydrochloric acid is added to it. In order to extract the pepsin in a pure state, acetate of lead is to be added to this liquor; the precipitate is washed, diffused in water, and decomposed by a current of hydrosulphuric acid. The filtered liquor is colourless, and has an acid action, owing to the acetic acid.

When this liquor is evaporated at $95^{\circ}$ Fahrenheit, to the consistence of a syrup, and absolute alcohol is added to it; an abundant flocculent precipitate is formed, which on drying lenves a yellow gummy matter, which does not attract moisture, and is pure pepsin.

This substance easily dissolves in water, and the solution, even though it contains only 1-5000, dissolves slightly acidulated white of egg, in about six or eight hours. The aqueous solution has an acid action owing to some acetic acid which remains intimately combined with it; it cannot be separated from the pepsinate of lead, even by repeated washings. By ebullition this liquor loses its digestive powers. If the free acid which it contains is cautiously saturated by potash, a small quantity only of which is requisite, flocculi are deposited, and the digestive power is also lost.

The alkalies cautiously added to the solution of pepsin, till the free acid is saturated, occasion the formation of flocculi, and the liquor has no acid action. Sulphuric acid in small quantity produces white flocculi, which redissolve in a slight excess of the acid; by the addition of a further quantity, fresh flocculi are produced; hydrochloric and nitric acids produce the same effects.

Perchloride of mercury occasions a precipitate which is redissolved by an excess of it; the proto- and persulphates of iron and the sulphate of copper precipitate pepsin. Alcohol precipitates it from a concentrated solution. According to M. Pappenheim, this precipitate dissolves in hydrochloric acid, and dissolves boiled white of egg. M. Wasmann confirms this statement of the digestive power of the precipitate formed by alcohol, while, according to M. Schwann, alcohol destroys the digestive property of pepsin.

Pepsin is recognized by the precipitates which its solution gives with diluted acids, and which redissolve in an excess of the acids, and by its giving no precipitate with ferrocyanide of potassium. It is distinguished from albumen by the precipitates which its solution yields on the addition of water and hydrochloric acid; and from caseum, by its acid solutions yielding no precipitate with ferrocyanide of potassium.-Journal de Chimie Médicale, Aoùt, 1840.

\section{DECREPITATING SALT OF WIELICZKA. BY H. ROSE.}

This salt was first noticed by M. Boue, who sent a specimen of it to M. Dumas ; it is distinguished from common salt by decrepitating not only when it is heated, but when dissolved in water; during solution decrepitation occurring with the disengagement of gas. It is evident that this gas was confined in the salt in a state of strong 
condensation; and this is the cause which occasions the decrepitation both by heat and solution in water.

M. Dumas found that the gas extricated from this variety of salt, when mixed with oxygen gas, detonated like hydrogen; nevertheless he supposed carbon to exist in it. He had not a sufficient quantity of the salt to examine more minutely the gas condensed in these crystals.

M. H. Rose received from Professor Zeuschner of Krakaut, a considerable quantity of the detonating salt, and he has been enabled to repeat and verify the experiments of M. Dumas. The different portions of salt did not all give the same quantity of gas when dissolved in water. The maximum, as stated by M. Dumas, amounted to about half the volume of the salt.

The gas, when burnt with oxygen, gave nearly the same composition as pond gas $\left(\mathrm{C} \mathrm{H}^{4}\right)$. This product is probably so condensed as to exist as a liquid or solid in the interior of the salt, and resumes the state of an elastic fluid at common pressures.

The property which this salt possesses ought in future to direct the attention to a great number of minerals which occur in nature, and which decrepitate in the fire without our being able to attribute it to the disengagement of moisture. It may be that the cause of the decrepitation is the disengagement of a gas condensed in the mineral.-Ann. de Chim. et de Phys., Mars, 1840.

\section{METEOROLOGICAL OBSERVATIUNS FUR AUG. 1840.}

Chiswick.-Aug. 1, 2. Very fine. 2-9. Hot and dry. 10. Very fine. 11. Showery. 12. Cloudy: rain. 13. Cloudy. 14. Rain. 15. Very fine : showery. 16. Fine. 17. Boisterous with heavy rain. 18. Cloudy. 19. Heavy rain: cloudy and fine. 20. Fine. 21. Foggy : very fine. 22. Foggy. 2526. Very fine. 27. Foggy : fine. 28. Slight fog : rain. 29. Foggy. 30, 31. Cloudy and fine. The mean temperature of the month was nearly $2^{\circ}$ above the average.

Boston.-Aug. 1-3. Fine. 4. Cloudy. 5-10. Fine. 11. Rain. 12, 19. Fine. 14. Cloudy. 15. Stormy : rain P.M. 16. Fine. 17. Stormy : rain early A.M.: rain with thunder and lightning r.M. 18. Stormy. 19, 20. Cloudy. 21. Fine : quarter past three P.M. thermometer $80^{\circ}$. 22. Cloudy : rain P.M. : lightning at night. 23, 24. Fine. 25. Fine: rain P.м. 26, 27. Cloudy. 28. Fine. 29. Cloudy. 30. Fine: rain P.M. 31. Cloudy: rain A.M.

N.B. The warmest August since 1826.

Applegarth Manse, Dumfries-shire.-Aug. 1, 2. Very fine. 3. Mild : showery A.M. 4. Fine. 5. Sultry. 6. Sultry : heat oppressive. 7-9. Sultry. 10. Wet and boisterous P.M. 11. Showery. 12-14. Occasional showers. 15. Fair throughout. 16. Much rain P.M. 17. Heavy rain: thunder: high flood. 18. Fine drying day. 19. Fine, with one slight shower. 20. Drizzling all day. 21. Fine : rain P.M. 22, 23. Fine and fair all day. 24, 25. Showery. 26. Fair all day and clear sky. 27. Wet P.M. 28. Fair all day. 29. Drizzling all day. 30. Fine and fair all day. 31. Remarkably fine harvest day.

Sun shone out 27 days. Rain fell 15 days. Thunder 1 day.

Wind north-west 5 days. East-south-east 1 day. South-east $4 \frac{\pi}{2}$ days. South 7 days. South-south-west 4 days. South-west $8 \frac{1}{2}$ days. Variable 1 day.

Calm 12 days. Moderate 11 days. Brisk 5 days. Boisterous 8 days. Mean temperature of the month............ $57^{\circ} \cdot 60$

Mean temperature of August, $1839 \ldots \ldots . \quad 55 \cdot 70$

Mean temperature of spring water ..... $52 \cdot 53$ 